\title{
Experimental Study on Properties of Rock-Cemented Coal Gangue-Fly Ash Backfill Bimaterials with Different Coal Gangue Particle Sizes
}

\author{
Yabo Wang, ${ }^{1,2}$ Dawei Yin $\mathbb{D}^{1,2}$ Shaojie Chen, ${ }^{1}$ Libo Zhang, ${ }^{1}$ Dongyi Liu, ${ }^{3}$ and Yanhua Sun ${ }^{4}$ \\ ${ }^{1}$ State Key Laboratory of Mine Disaster Prevention and Control, Shandong University of Science and Technology, \\ Qingdao 266590, China \\ ${ }^{2}$ Key Laboratory of Safety and High-Efficiency Coal Mining, Ministry of Education, Anhui University of Science and Technology, \\ Huainan 232001, China \\ ${ }^{3} 801$ Hydrogeological Engineering Geology Brigade of Shandong Bureau of Geology and Mineral Resources, Jinan 250014, China \\ ${ }^{4}$ School of Civil Engineering, Guizhou University of Engineering Science, Bijie 551700, China
}

Correspondence should be addressed to Dawei Yin; 949251142@qq.com

Received 4 July 2020; Revised 30 August 2020; Accepted 12 September 2020; Published 24 September 2020

Academic Editor: Qian Yin

Copyright (c) 2020 Yabo Wang et al. This is an open access article distributed under the Creative Commons Attribution License, which permits unrestricted use, distribution, and reproduction in any medium, provided the original work is properly cited.

Properties of rock-cemented coal gangue-fly ash backfill (CGFB) bimaterials determine the effects of strip CGFB mining on controlling the surface subsidence in coal mines, which are affected by the coal gangue particle size in CGFB. In this paper, uniaxial compression tests were conducted on the coarse sandstone-CGFB composite samples with different coal gangue particle sizes, and their strength, acoustic emission (AE), and failure characteristics were investigated. The uniaxial compressive strength (UCS) and elastic modulus of the composite sample decreased with the coal gangue particle size. The strength of the composite sample is mainly dependent on that of CGFB in it, affected by interactions between CGFB and coarse sandstone. The deformation of the coarse sandstone weakened the damage accumulation within CGFB, resulting in the strength of the composite sample larger than that of CGFB. The average UCS values of composite samples with coal gangue particle sizes of $0 \sim 5 \mathrm{~mm}, 5 \sim 10 \mathrm{~mm}$, and $10 \sim 15 \mathrm{~mm}$, increased by $10.78 \%, 14.98 \%$, and $12.70 \%$ compared with CGFB in them, respectively. AE event signal regularity of the composite sample was divided into three stages: rising period, calm period, and active period. The intensity and frequency of AE event signals in three periods were strengthened with the coal gangue particle size. The calm period can be taken as the precursory information for the failure and instability of composite sample under loading, whose duration became shortly with the coal gangue particle size. The rebound deformation of coarse sandstone caused the fluctuations of AE event signals at the later stage of active period. The failures of the composite sample occurred within CGFB, and no obvious failures were found in the coarse sandstone. The CGFB mainly experienced the splitting failure accompanying by varying degrees of surface spalling failures. The broken degree of CGFB increased with the coal gangue particle size, and the largest weight ratio of CGFB fragments (chips) after failure was determined by the coal gangue particle size.

\section{Introduction}

The surface subsidence induced by the underground coal mining not only destroys the ecological environment and the surface buildings (Figure 1) but also associates with many serious hidden troubles [1-9]. Many coal mines have used the backfill mining to control the surface subsidence. The cemented coal gangue-fly ash backfill (CGFB), mainly consisting of the cement, fly ash, coal gangue, and water, has been widely used in the field of backfill mining due to its high early and cured strengths and good pumping performances [10-14]. In order to reduce the quantity and cost of backfill materials, the strip CGFB mining is used to control the surface subsidence in many Chinese coal mines. Its basic principle is that some strip CGFB bodies with regular intervals are arranged in the goaf to support the overlying strata and to control the surface subsidence [15-18], as shown in Figure 2. If the intervals between CGFB bodies 


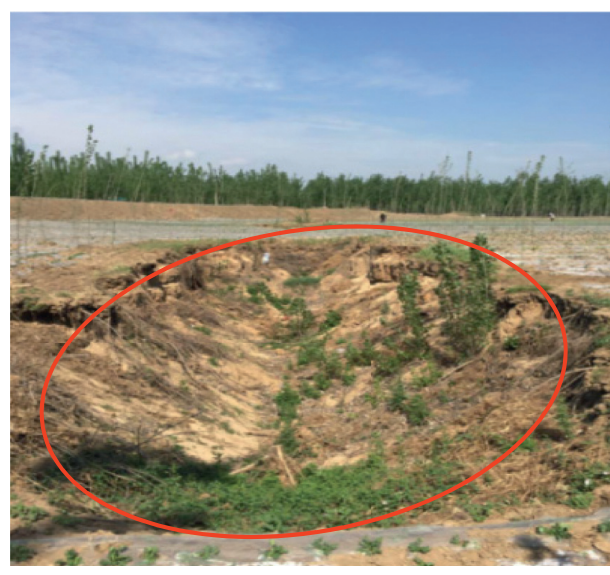

(a)

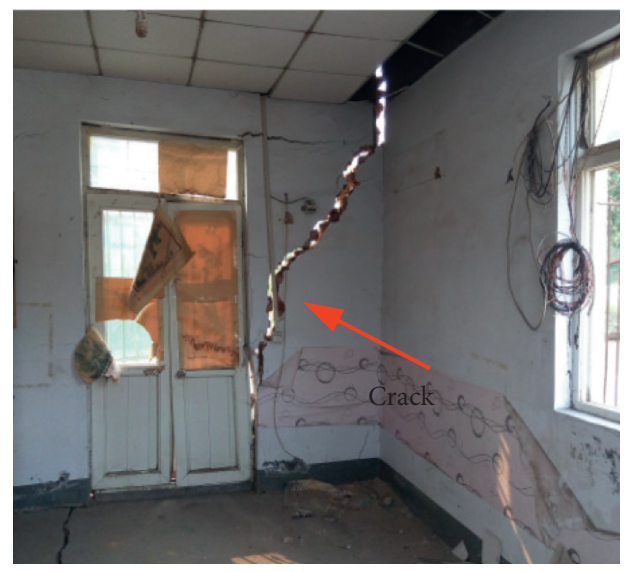

(b)

FIgURE 1: Damages of surface subsidence caused by underground coal mining. (a) Collapse pit. (b) Building damage.

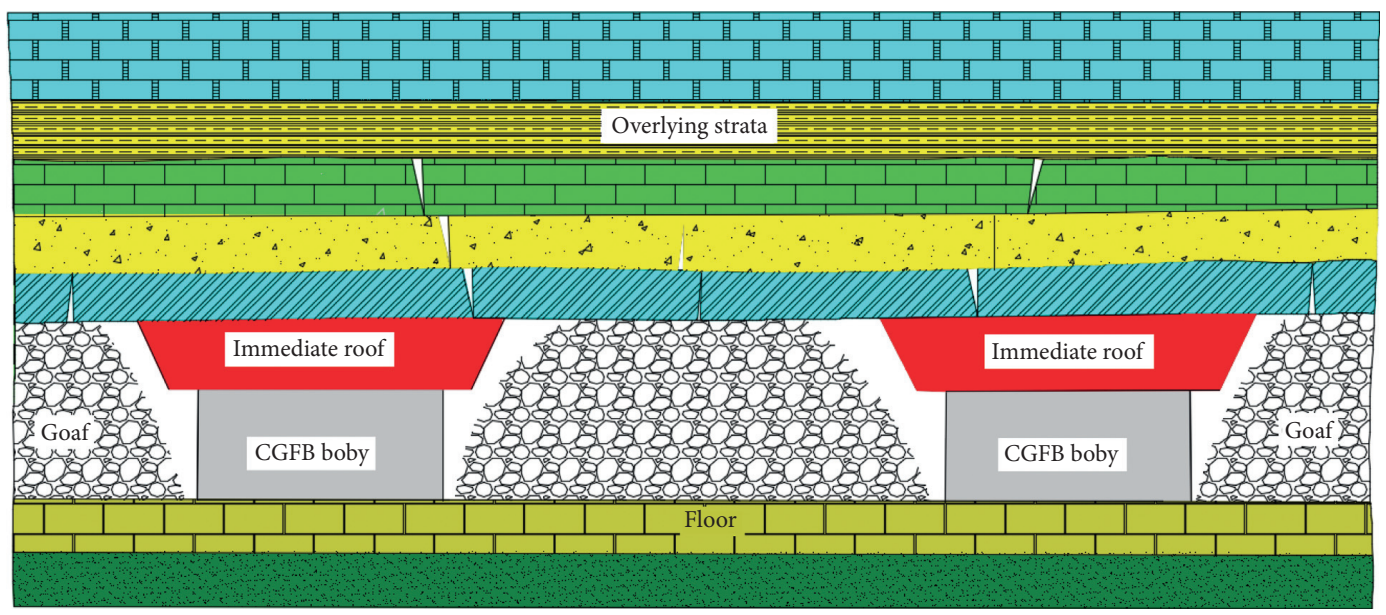

FIGURE 2: Basic principles of strip CGFB mining.

exceed the caving step distance of the immediate roof, the immediate roof will collapse, and then the broken rocks will backfill the goaf. Now, the immediate roof-CGFB body composite structures are formed in the goaf to support the overlying strata and to control the surface subsidence. The properties of these composite structures determine the effects of controlling surface subsidence by the strip CGFB mining, which are necessary to investigate.

However, previous investigations pay more attention to the properties of pure CGFB, and some interesting achievements were obtained. Du et al. [19] analyzed the volume resistivity, pore solution resistivity, UCS, and elastic modulus of CGFB at early age, and its hydration process was divided into the adsorption period, dissolution period, condensation period, and hardening period. Qi et al. [20, 21] investigated the effects of the fine coal gangue and fly ash contents on properties of CGFB, including the rheological property, bleeding index, UCS, and dry shrinkage. Feng et al. [22] studied the influences of the wasted concrete coarse aggregate on the performances of CGFB and analyzed the feasibility of the waste concrete coarse aggregate to replace coal gangue for CGFB. And they also investigated the optical-acoustic-stress responses of CGFB during the failure process under loading $[23,24]$. Based on the Nishihara model, Sun et al. [25] established the creep constitutive model of CGFB and analyzed the effects of the chloride corrosion on creep characteristics of CGFB [26]. Wu et al. [27-29] believed that the properties of CGFB were subjected to the thermal $(\mathrm{T})$, hydraulic $(\mathrm{H})$, mechanical $(\mathrm{M})$, and chemical (C) processes, and they studied the THMC effects on the mechanical properties of CGFB. Furthermore, they also discussed the transportability and pressure drop of fresh CGFB slurry in the pipe loop [30]. Cui et al. [31], Liu et al. [32], and Sun et al. [33] tested the effects of the sulfate and chloride corrosions on the properties of CGFB, respectively, and they analyzed the influence mechanisms from a microscopic perspective. Through the uniaxial compression tests on the CFGB samples with a large size (length $\times$ width $\times$ height $=800 \mathrm{~mm} \times 800 \mathrm{~mm} \times 1600 \mathrm{~mm}$ ), Du et al. $[10,11]$ investigated the bearing mechanism and 
stability of CGFB column in partial backfill engineering. Based on the CGFB, a new type of backfill materials called geopolymer cemented coal gangue-fly ash backfill (GCGFB) was invented by Sun et al. [26, 34, 35], which consisted of coal gangue, fly ash, cement, slag, and alkaline activator mixed with sodium hydroxide and sodium silicate, and its properties were studied, including the localized deformation, microstructure, and creep properties.

The aforementioned investigations are important for understanding the properties of CGFB. While few studies have focused on the properties of the rock-CGFB bimaterials, Chen et al. [18] preliminarily investigated the mechanical properties of sandstone-CGFB bimaterials. Other studies have investigated the shear failure characteristics $[36,37]$, failure mechanisms $[38,39]$, and tensile performances of the rock-concrete bimaterials [40].

The coal gangue particle size in CGFB affects the whole properties of rock-CGFB bimaterials. In this paper, the coarse sandstone-CGFB composite samples with different coal gangue particle sizes of $0 \sim 5 \mathrm{~mm}, 5 \sim 10 \mathrm{~mm}$, and $10 \sim 15 \mathrm{~mm}$ were prepared, respectively, and uniaxial compression tests were conducted on them to investigate their strength, acoustic emission (AE), and failure characteristics.

\section{Materials and Methods}

2.1. Raw Materials. In this investigation, the coarse sandstone was used as the rock material, which was collected from the immediate roof in the 4338 working face of Daizhuang Coal Mine of Shandong Province, China. The CGFB composed of cement, fly ash, coal gangue, and water. Among them, cement was Portland cement of grade 42.5 obtained from Shandong Rizhao No. 3 cement plant. Fly ash was the secondary fly ash obtained from the Shandong Huangdao Power Plant, and the coal gangue was collected from the Daizhuang Coal Mine. Water was the tap water obtained from the State Key Laboratory of Mine Disaster Prevention and Control, Shandong University of Science and Technology. The mineral components of coal gangue, fly ash, and cement in this investigation are shown in Figure 3.

2.2. Sample Preparation. In order to study the properties of rock-CGFB bimaterials with different coal gangue particle sizes, the coal gangue particle sizes were taken as $0 \sim 5 \mathrm{~mm}$, $5 \sim 10 \mathrm{~mm}$, and 10 15 $\mathrm{mm}$ in this investigation, respectively. According to previous investigations [18, 31, 32], the mass ratio of cement to fly ash to coal gangue was $1: 4: 6$ in CGFB, and the solid materials comprised $78 \%$ of the total weight of CGFB. For convenience, both coarse sandstone and CGFB had a same height of $50 \mathrm{~mm}$ in the standard composite samples $(\Phi 50 \times 100 \mathrm{~mm})$. The preparation processes of coarse sandstone-CGFB composite samples were described as follows.

The coarse sandstone blocks were firstly drilled into the cylindrical samples with a diameter of $50 \mathrm{~mm}$ using a ZS-100 fully automatic drilling and coring machine. Then, using a
QS-2 stone-sawing machine, these cylindrical samples were cut into $\Phi 50 \times 50 \mathrm{~mm}$. Both ends of these coarse sandstone samples were trimmed flat and smooth using a LM-200 vertical stone-grinding machine to provide smooth surfaces, i.e., the nonparallelism of the two ends was less than $0.01 \mathrm{~mm}$, and the diameter deviation of the ends was no greater than $0.02 \mathrm{~mm}$ [41]. The coarse sandstone samples of $\Phi 50 \times 50 \mathrm{~mm}$ were used to prepare the composite samples. Each coarse sandstone sample was then placed in the moulds of $\Phi 51 \times 50 \mathrm{~mm}$. The well-stirred mixtures of CGFB with different coal gangue particle sizes were directly poured into the moulds. Composite samples were removed from moulds after $24 \mathrm{~h}$ and cured for $28 \mathrm{~d}$ in a curing box with a temperature of $20 \pm 2^{\circ} \mathrm{C}$ and a humidity of $80 \%$. The CGFB end of the composite sample was trimmed with a LM-200 vertical stone-grinding machine to meet experimental requirements, and its sides were mechanically sanded with a fine emery paper to make it $50 \mathrm{~mm}$ in diameter. Now, the coarse sandstone-CGFB composite samples were well prepared, as shown in Figure 4. Nine composite samples were prepared and categorized under groups A, B, and C, corresponding to the composite samples with the coal gangue particle sizes of $0 \sim 5 \mathrm{~mm}, 5 \sim 10 \mathrm{~mm}$, and $10 \sim 15 \mathrm{~mm}$, respectively.

2.3. Testing System. The testing system consisted of a loading system, an AE monitoring system, and a digital video camera synchronized to have the same time stamps in each test, as shown in Figure 5. An AG-X250 servo-controlled testing system, as the loading system, was used to carry out the uniaxial compression tests on coarse sandstone-CGFB composite samples with different coal gangue particle sizes. A double screw loading structure is used for working flexibility; therefore, this testing system can execute the conventional compression, tensile, or any other mechanical tests, as required [41-45]. The maximum testing load of the testing system can reach $250 \mathrm{kN}$. Considering that the composite structures of rock-CGFB body support the overlying strata for a long time, a displacement loading method was adopted in these tests at a loading rate of $0.0005 \mathrm{~mm} / \mathrm{s}$.

According to the test method provided by Chen et al. $[41,42]$, the fracturing and failure propagation processes of composite samples under uniaxial loading were monitored using a PCI-2 AE monitoring system by MISTRAS and a SONY portable digital camera. The main amplifier, threshold value, and floating threshold of AE monitoring system were $40 \mathrm{~dB}, 45 \mathrm{~dB}$, and $6 \mathrm{~dB}$, respectively. The $\mathrm{AE}$ probe was $\mathrm{R} 3 \alpha$, whose resonant and sampling frequencies were $20 \sim 100 \mathrm{kHz}$ and $10^{6} / \mathrm{s}$, respectively [18]. One $\mathrm{AE}$ sensor was fixed to the surface of the coarse sandstone using the adhesive tape. Vaseline was applied between the sensor and sample surface to improve coupling conditions. The pencil-lead fracture method proposed by ASTM (American Society for Testing and Materials) was employed to calibrate the AE system [26]. Finally, the fragment (chip) weight distributions of composite samples were analyzed after failure. 


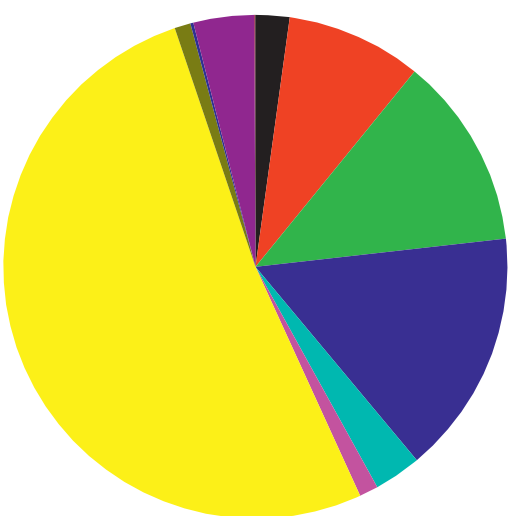

$\mathrm{Na}_{2} \mathrm{O}-2.177 \%$
$\mathrm{MgO}-8.706 \%$
$\mathrm{Al}_{2} \mathrm{O}_{3}-12.340 \%$
$\mathrm{SiO}_{2}-15.722 \%$
$\mathrm{SO}_{3}-3.025 \%$
$\mathrm{~K}_{2} \mathrm{O}-1.203 \%$
$\mathrm{CaO}-51.643 \%$
$\mathrm{TiO}_{2}-1.031 \%$
$\mathrm{MnO}-0.190 \%$
$\mathrm{Fe}_{2} \mathrm{O}_{3}-3.891 \%$
$\mathrm{ZnO}-0.072 \%$

(a)
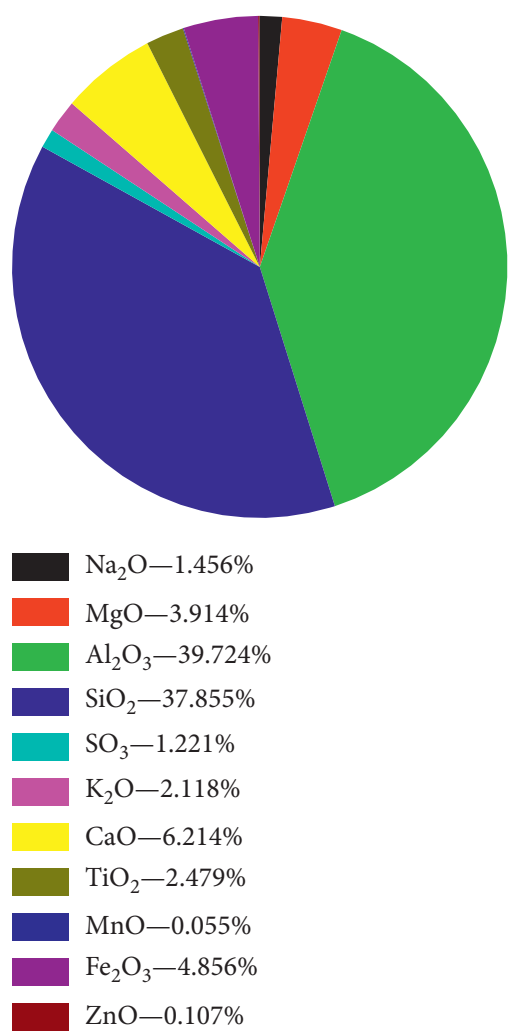

(b)
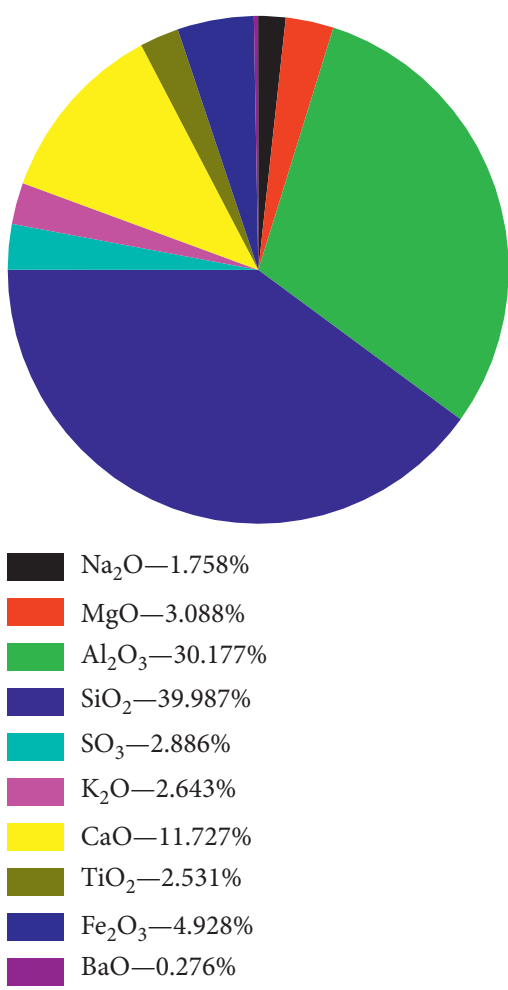

(c)

Figure 3: Mineral components of (a) cement, (b) fly ash, and (c) coal gangue.

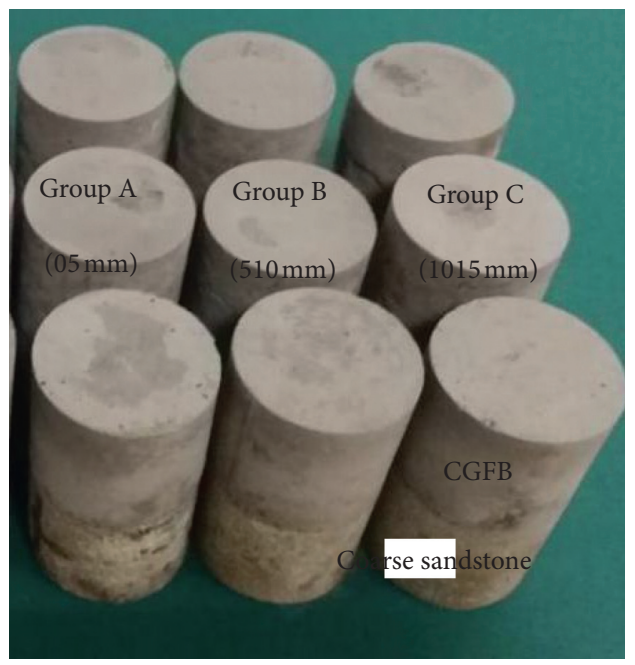

FIGURE 4: Coarse sandstone-CGFB composite samples with different coal gangue particle sizes.

\section{Results Analysis}

3.1. Strength Characteristics of Composite Samples. The UCS values and elastic moduli (the slope of stress-strain curve at $40 \%-60 \%$ of peak stress) of coarse sandstone-CGFB composite samples with different coal gangue particle sizes are compared in Figures 6(a) and 6(b), respectively.
In Figure 6, the coal gangue particle size seriously affects the UCS and elastic modulus of the composite sample. The average UCS and elastic modulus of group A (coal gangue particle size of $0 \sim 5 \mathrm{~mm}$ ) are the largest in three groups, which are $4.705 \mathrm{MPa}$ and $0.69 \mathrm{GPa}$, respectively, while the average UCS and elastic modulus of group C (coal gangue particle size of $10 \sim 15 \mathrm{~mm}$ ) are the smallest with $2.802 \mathrm{MPa}$ and $0.51 \mathrm{GPa}$, respectively. The average UCS and elastic modulus of group B (coal gangue particle size of $5 \sim 10 \mathrm{~mm}$ ) are $3.745 \mathrm{MPa}$ and $0.60 \mathrm{GPa}$, respectively. Compared with group A, the average UCS values of groups B and C decrease by $20.40 \%$ and $40.45 \%$, respectively, and the corresponding average elastic moduli decrease by $10.44 \%$ and $22.09 \%$, respectively. These illustrate that the strength and elastic modulus of the composite sample generally decrease with the coal gangue particle size, which are consistent with the effects of the coal gangue particle size on that of pure CGFB samples [20].

3.2. Failure Characteristics of Composite Samples. Typical images of macrofailure for the coarse sandstone-CGFB composite samples with different coal gangue particle sizes are shown in Figure 7. In Figure 7, the failures of composite samples mainly occur within the CGFB, and we observe no evidence of the fracturing or failure in the coarse sandstone. These illustrate that the failure and instability of CGFB determine the overall instability of the composite sample. 


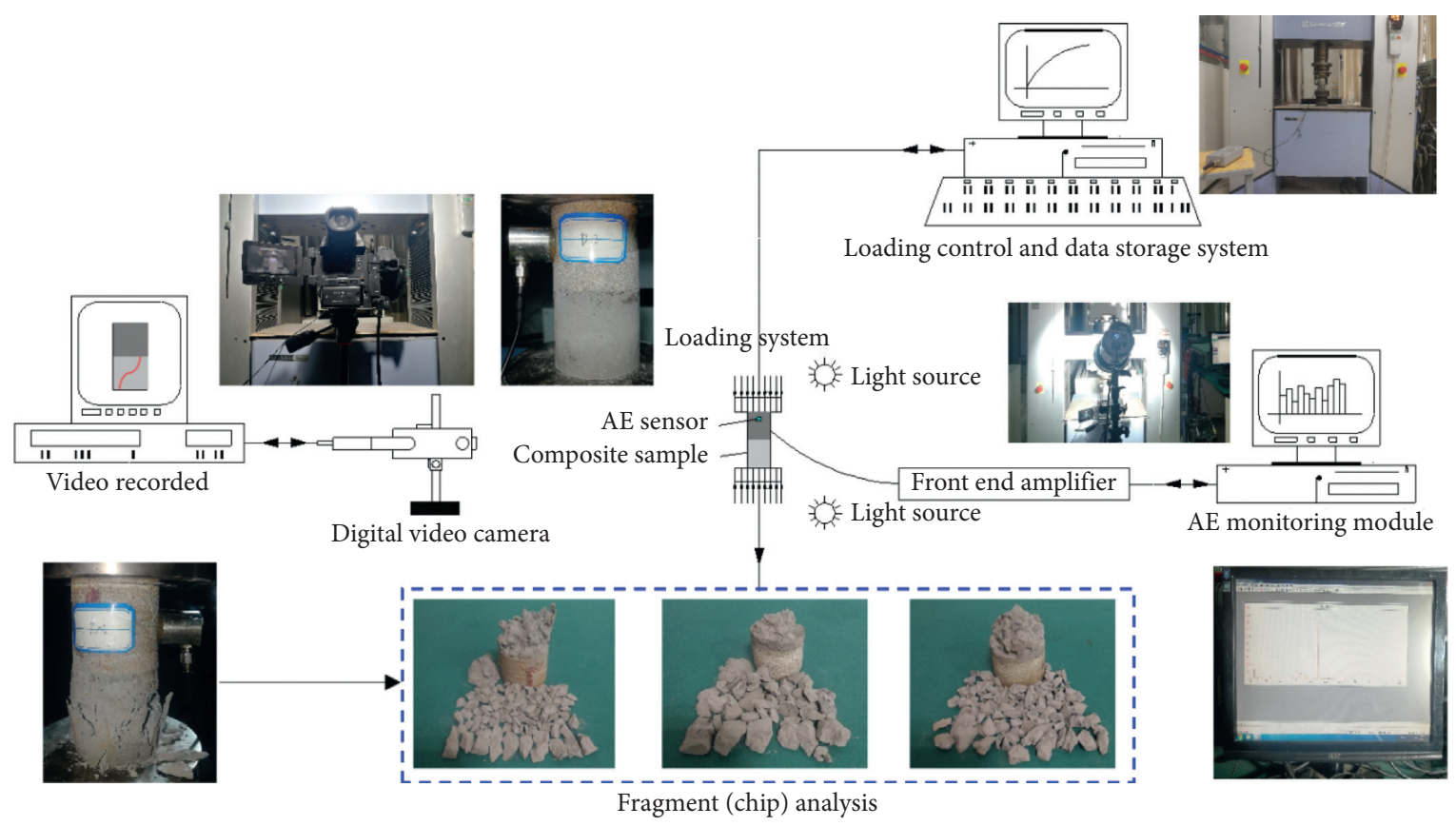

Figure 5: Test system for the composite samples.

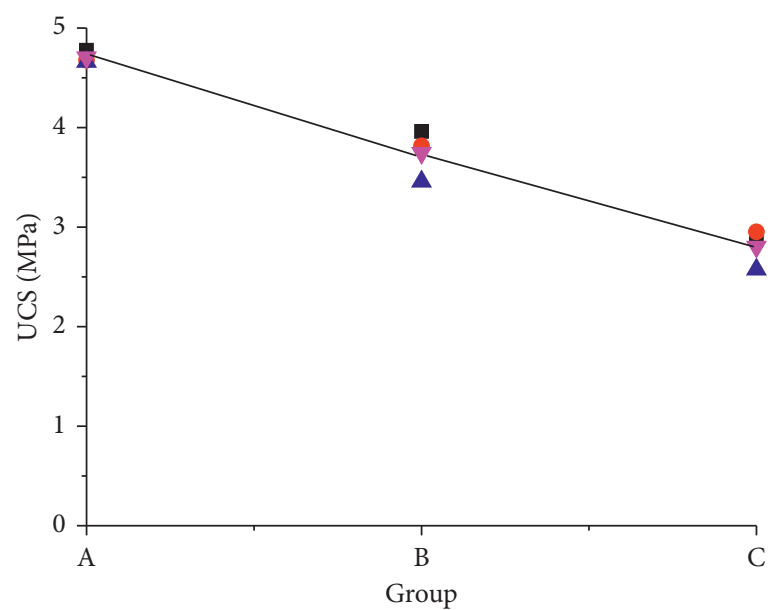

- UCS of no.1 sample in each group

- UCS of no.2 sample in each group

A UCS of no.3 sample in each group

$\nabla$ Average UCS of each group

(a)

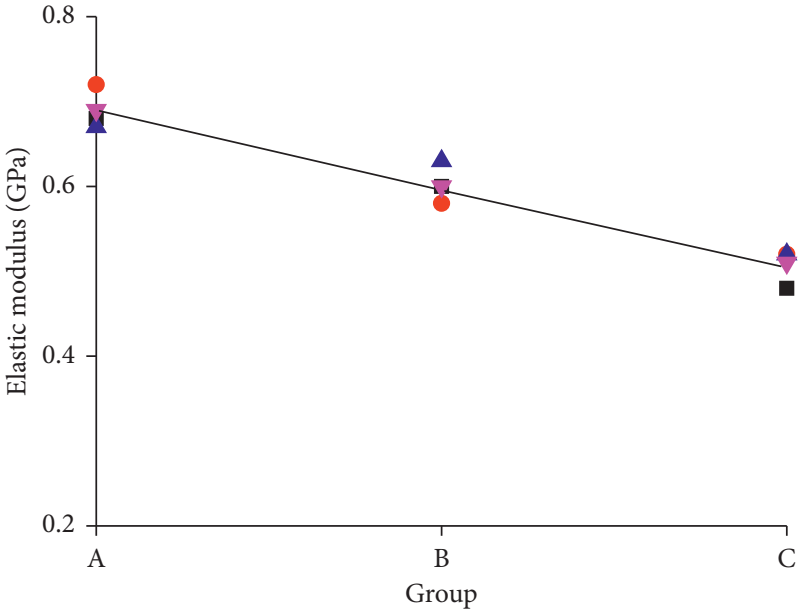

- Elastic modulus of no.1 sample in each group

- Elastic modulus of no.2 sample in each group

A Elastic modulus of no.3 sample in each group

$\nabla$ Average elastic modulus of each group

(b)

FIgURE 6: Variations in (a) UCS and (b) elastic modulus of composite samples with coal gangue particle size.

The failure characteristics reflect the strength properties of samples [41-43]. Therefore, the whole strength of composite sample mainly depends on that of CGFB in it. The tensile cracks are clearly found in CGFB, illustrating that the CGFB experiences the splitting failure. Meanwhile, some local surface spalling failure zones are also found in the CGFB. Therefore, the CGFB in the composite sample attains the splitting failure accompanied by the varying degrees of local surface spalling failures. With an increase of the coal gangue particle size, the broken degree of CGFB generally increases.

After failure, CGFB in the composite samples produces the fragments (chips) with different sizes. In order to further analyze the failure characteristics of composite samples, the fragment (chip) weight distributions of CGFB after failure were counted and investigated. The fragment (chip) weight distributions were divided into four groups: $0 \sim 5 \mathrm{~mm}$, 


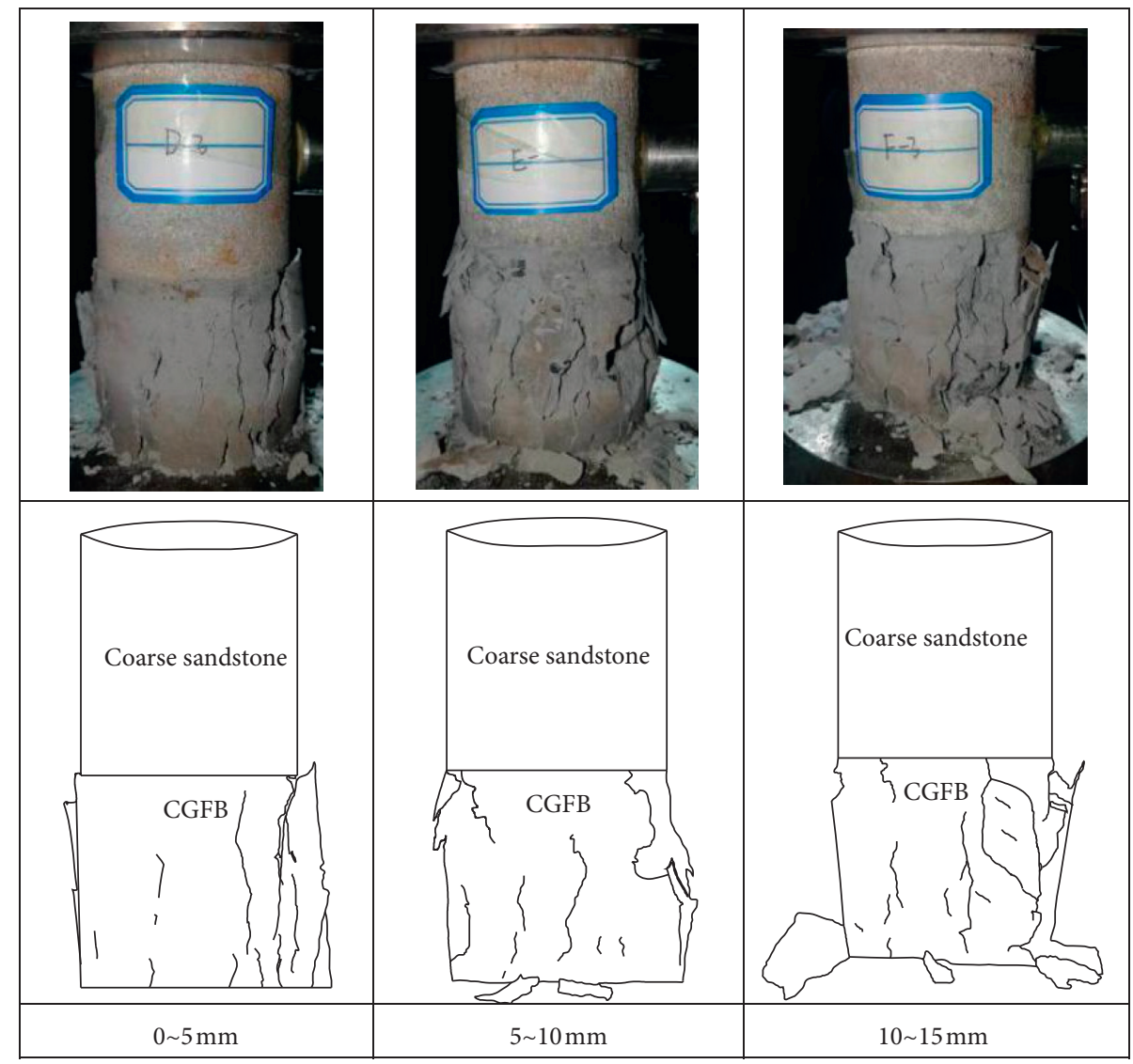

Figure 7: Typical macrofailure patterns of composite samples.

5 10 mm, 10 15 mm, and >15 mm. CGFB fragments (chips) with the size less than $5 \mathrm{~mm}$ were screened by the sieve with corresponding aperture. For the CGFB fragments with the size larger than $5 \mathrm{~mm}$, their sizes were firstly measured with a vernier caliper and were weighed. Finally, the fragments (chips) in each distribution were weighed, respectively, and then were processed through the average value method. The CGFB fragment (chip) weight distributions are shown in Figure 8.

In Figure 8, the weight ratios of CGFB fragments (chips) within $0 \sim 5 \mathrm{~mm}$ in three groups are $50.51 \%, 21.01 \%$, and $15.47 \%$, respectively, showing a decreasing trend with the coal gangue size. The weight ratio of CGFB fragments within $5 \sim 10 \mathrm{~mm}$ is the largest $(55.26 \%)$ in group B, and the weight ratio within $10 \sim 15 \mathrm{~mm}$ is the greatest $(48.93 \%)$ in group C. These illustrate that the coal gangue particle size affects the fragmentation form of CGFB in the composite samples, i.e., the coal gangue particle size determines the largest weight ratio of CGFB fragments after failure in this investigation. Meanwhile, these again display that the overall strength of composite sample is determined by that of CGFB in it.

3.3. AE Characteristics of Composite Samples. Figure 9 shows the AE characteristics of coarse sandstone-CGFB composite samples with different coal gangue particle sizes.
In Figure 9, the loading processes of composite samples can be divided into three stages: rising period, calm period, and active period according to their AE characteristics. For the uniaxial stress-strain curve of composite sample, the rising period corresponds to the initial compaction stage and the early stage of linear elastic; the calm period presents the later stage of linear elastic; and the active period corresponds to plastic yield and postpeak failure stages [46].

In the rising period, the voids and cracks in the coarse sandstone and CGFB are compacted, which are also accompanied by the frictions between the coal gangue particles. And microcracks initiate and stably propagate in this stage. Therefore, the intensity and frequency of AE event signals are strong in this period, exhibiting the large fluctuations in peak values. At the later stage of rising period, the intensity and frequency of $\mathrm{AE}$ event signals are slightly weakened. CGFB with large coal gangue particle sizes contains more voids and cracks compared that with small coal gangue particle sizes $[20,21]$. The stress concentration easily appears around the defects in the CGFB with large coal gangue particle sizes, and microcracks readily initiate from the defects. Thus, the intensity and frequency of AE event signals for C-3 composite sample are the largest.

In the calm period, the $\mathrm{AE}$ event signals are stable with low intensity and frequency. Microcracks are formed inside the composite sample and stably propagate in this stage. However, this process is shorter compared with that of rising 


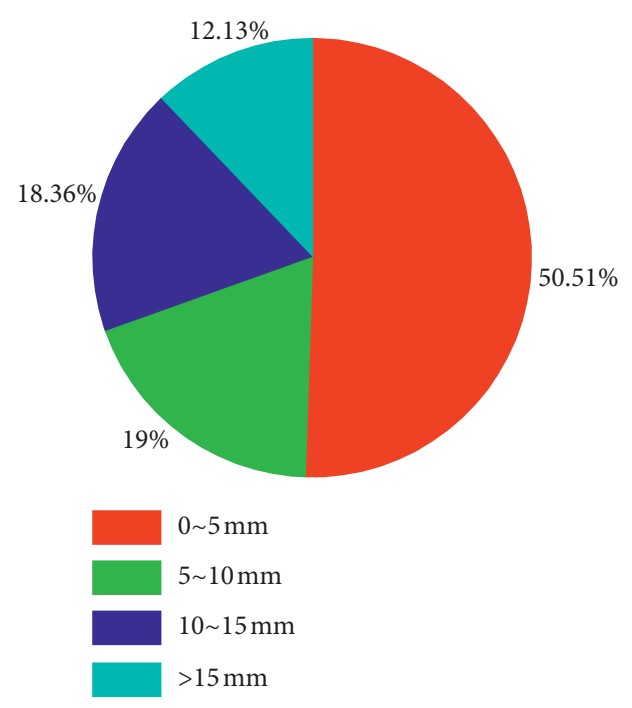

(a)

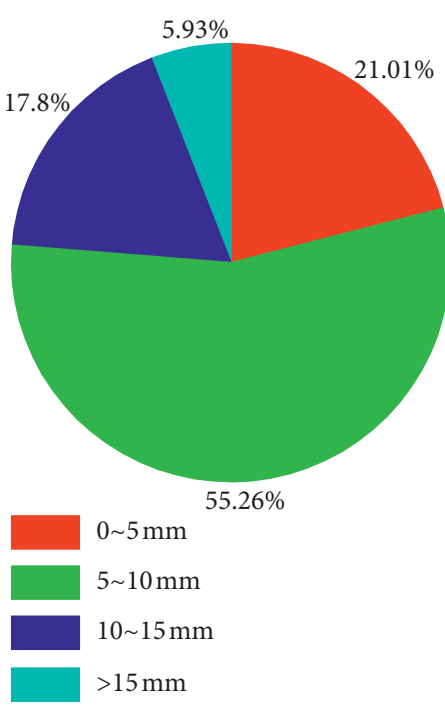

(b)

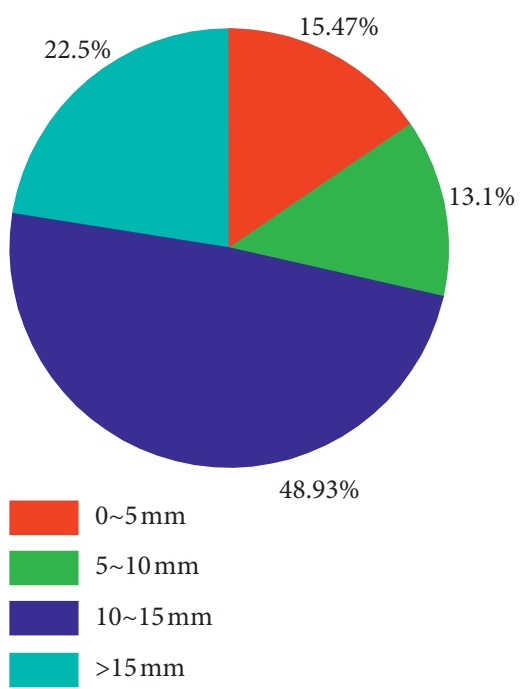

(c)

Figure 8: Fragment (chip) weight distributions of CGFB after failure. (a) Group A (0 5 mm). (b) Group B (5 10 mm). (c) Group C (10 15 mm).

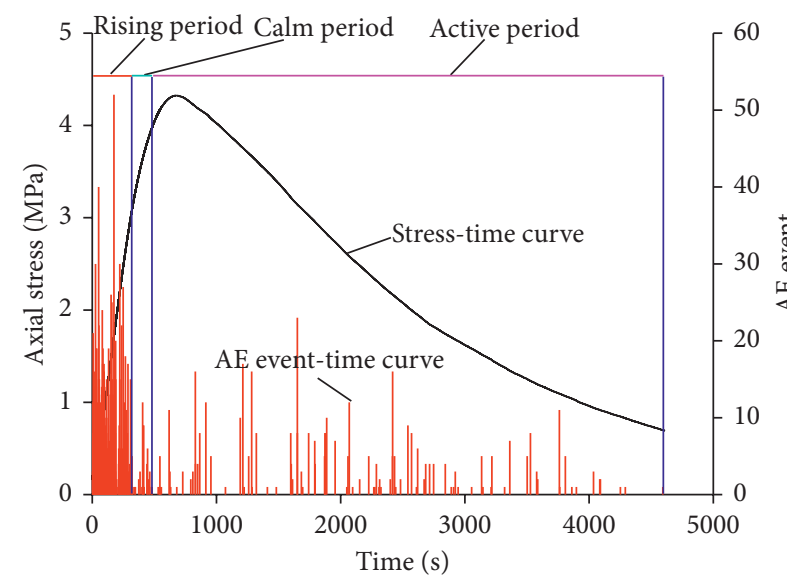

(a)

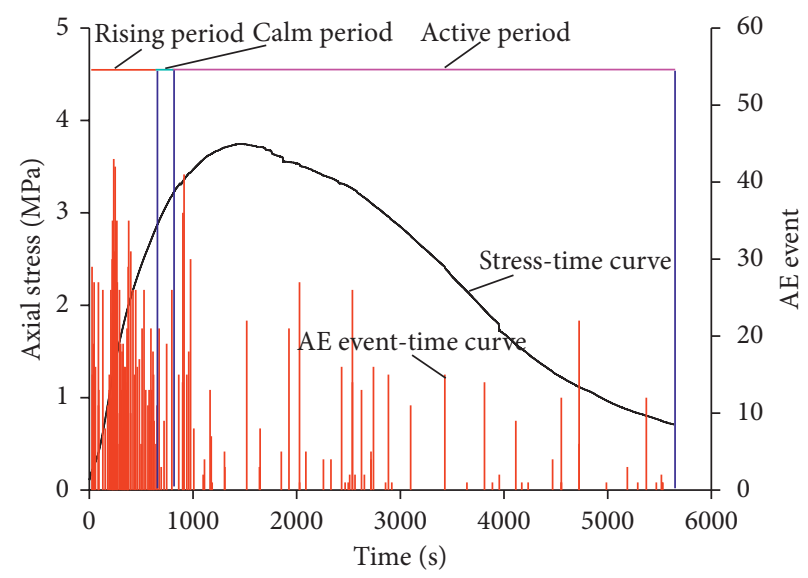

(b)

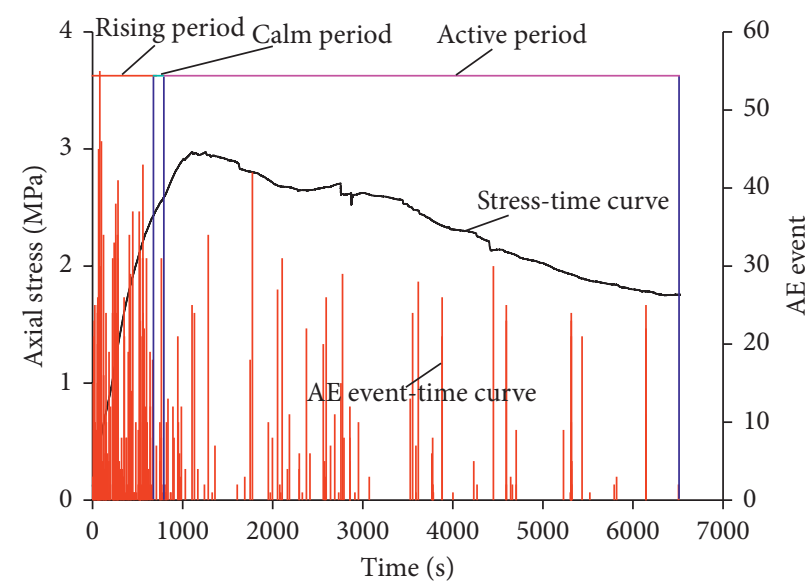

(c)

FIgURE 9: AE characteristics of composite samples. (a) A-3 composite sample. (b) B-1 composite sample. (c) C-3 composite sample. 


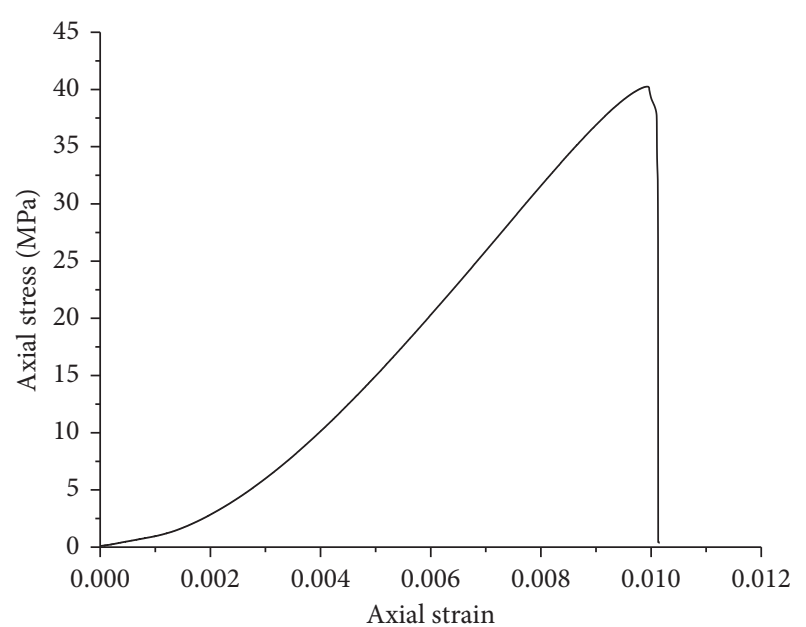

(a)

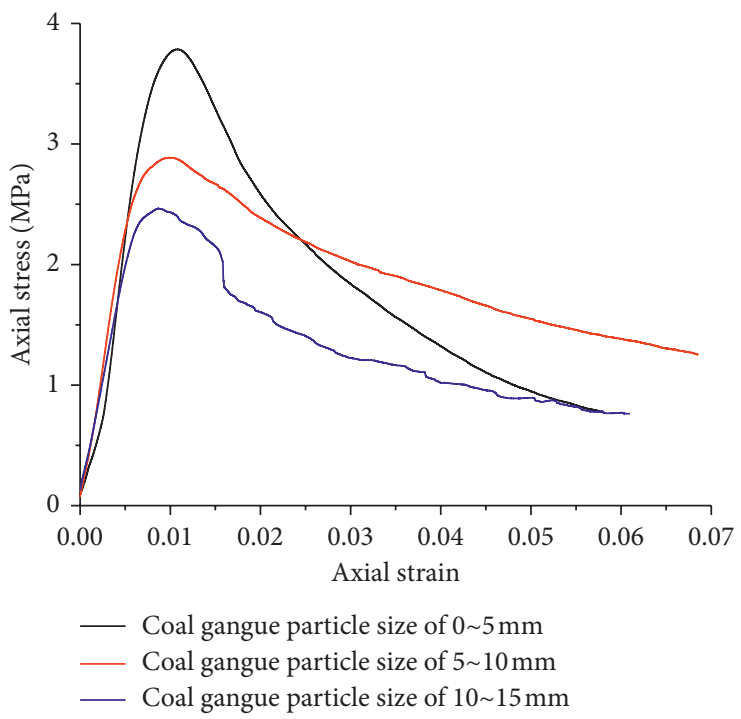

(b)

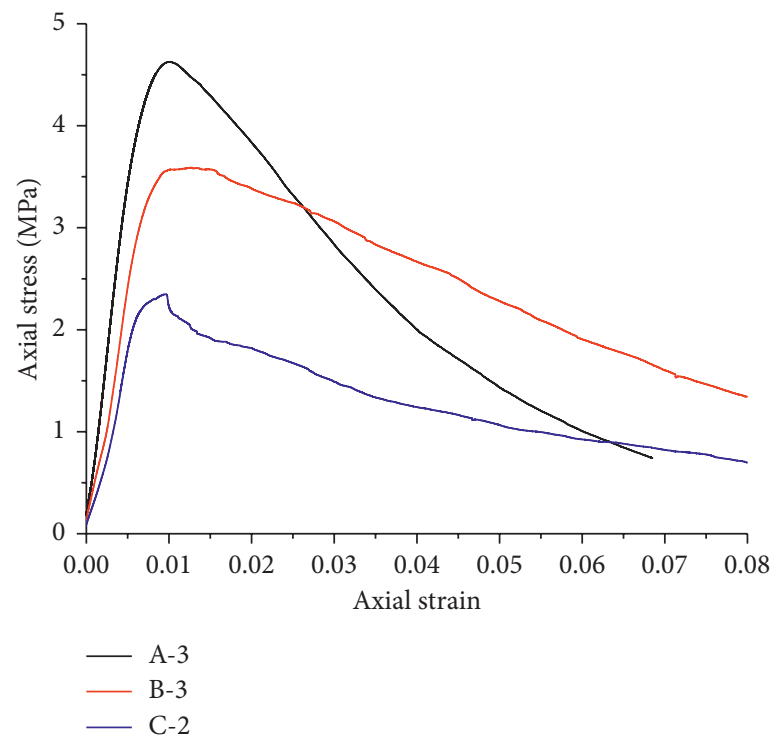

(c)

FIGURE 10: Stress-strain curves of (a) pure coarse sandstone sample, (b) pure CGFB samples, and (c) composite samples.

and active periods, which can be taken as the precursory information of failure and instability of composite sample under loading. The attention spans of the calm period for A-3, B-1, and C-3 composite samples are $202 \mathrm{~s}, 158 \mathrm{~s}$, and $118 \mathrm{~s}$, respectively, showing a decreasing trend with the coal gangue particle size. At the later stage of the calm period, $\mathrm{AE}$ event signals are slightly enhanced with some peaks, especially the C-3 composite sample. This is mainly due to local damage inside CGFB induced by propagation and coalescence of microcracks.

In the active period, the $\mathrm{AE}$ event signals are strengthened, exhibiting more significant fluctuations with large peak values. Microcracks begin to unstably propagate in the composite sample, and new macrocracks are formed on the surface of CGFB. The propagation and coalescence of macrocracks cause the splitting failure of CGFB, accompanied by local surface spalling failure. Finally, the failure and instability of CGFB cause the overall instability of the composite sample. However, the intensity and frequency of $\mathrm{AE}$ event signals at this stage are weaker than in the rising period mainly because the $\mathrm{AE}$ radiation waves are seriously attenuated and even blocked due to the aggregation of a large number of macrocracks before failure [23]. Meanwhile, due to the largest broken degree, the $\mathrm{AE}$ event signals for $\mathrm{C}-3$ composite sample are greater than A-3 and B-1 composite samples.

It is important to be pointed that due to its large strength, the coarse sandstone is still in the linear elastic stage after the 
failure of the composite sample. The fracture of CGFB will induce the rebound deformation of coarse sandstone, which promotes the further movement and failure of CGFB. This process appears before the occurrence of the main failure in the CGFB [41, 42], and thus the CGFB becomes more broken. Correspondingly, the $\mathrm{AE}$ event signals at the later stage of active period appear some fluctuations in peak values.

\section{Discussion}

From the failure characteristics of composite samples, their overall strength is determined by the strength of CGFB in them. The stress-strain curve can well reflect the mechanical properties of the sample under loading [42]. Figure 10 shows the stress-strain curves of coarse sandstone-CGFB composite samples, pure coarse sandstone, and CGFB samples $(\Phi 50 \times 100 \mathrm{~mm})$.

In Figure 10, the stress-strain curves of composite samples are similar to that of the pure CGFB samples, but are different to that of coarse sandstone samples. After the peak stress point, the composite samples and pure CGFB samples attain the plastic failure. The corresponding stress-strain curves decline slowly. While the pure coarse sandstone sample experiences the brittle failure after the peak stress point, the corresponding stress-strain shows a straight steep decline. These mean that the stress-strain characteristics of the composite sample mainly depend on the CGFB in it. And the strength of CGFB in the composite sample plays a major role in the whole strength of the composite sample. Based on the strength $\left(\sigma_{C}\right)$ of pure CGFB samples, the strength $\left(\sigma_{c}\right)$ of CGFB in the composite sample is [41]

$$
\sigma_{c}=\frac{\sigma_{C}(7+2(D / h))}{8},
$$

where $D$ and $h$ are the diameter and height of CGFB in the composite sample, respectively, and they are all $50 \mathrm{~mm}$. Figure 11 shows comparisons of $\sigma_{C}, \sigma_{c}$, and average UCS of each group composite sample.

In Figure 10, the average UCS of the composite sample is found to be larger than that of CGFB in it. Compared with $\sigma_{c}$, the average UCS values of groups A, B, and C decrease by $10.78 \%, 14.98 \%$, and $12.70 \%$, respectively. These are mainly induced by the interactions between coarse sandstone and CGFB in the composite sample.

It is well known that the instability and failure of the material show a damage accumulation process under loading [47-54]. The composite sample is an integrated body, and the coarse sandstone and CGFB in it both incur damage under uniaxial loading. Due to its lower strength, the CGFB is destroyed first, and once its internal damage accumulates beyond a threshold, it results in the instability of the composite sample. During this process, the coarse sandstone consumes some applied mechanical work as strain energy. Therefore, the internal damage accumulation in CGFB is limited. When the axial stress reaches $\sigma_{c}$, the accumulated damage in CGFB cannot cause its failure. In other words, the CGFB will be destroyed for an axial stress larger than $\sigma_{c}$. And the failure of CGFB causes the overall instability of the composite sample. Therefore, the strength

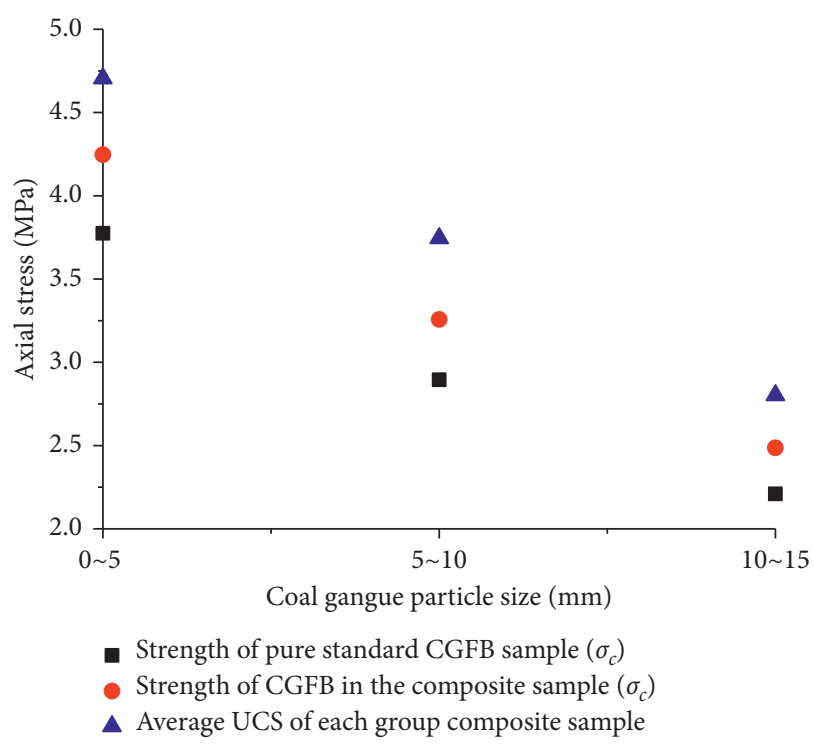

Figure 11: Comparisons of $\sigma_{C}, \sigma_{c}$, and average UCS of each group composite sample.

of the composite sample is greater than that of the CGFB in it.

The CGFB is a man-made material, which contains a greater number of natural defects, such as microcracks and holes. Under uniaxial loading, the stress concentrates in these defects of the CGFB, and the circumferential tensile stress $(\Delta \sigma)$ occurs perpendicular to the loading direction, as shown in equation (2) [55]. If the circumferential tensile stress exceeds the CGFB's tensile strength, the defects will develop into the macrotensile cracks on the CGFB surface. Propagation and coalescence of these tensile cracks finally induce the splitting failure of the CGFB and make the local part of the CGFB more broken to form the surface spalling failure. Finally, the failure and instability of CGFB induce the overall instability of the composite sample:

$$
\Delta \sigma=-\frac{1}{6} \frac{l}{\eta T} k \sigma\left(1-e^{-(\eta / l) t}\right)
$$

where $l$ is the defects scale in the CGFB, referring to the length, width, and depth of natural defects; $T$ is the continuous loading time; $\eta$ is the additional tensile stress relaxation rate; $k$ is the stress concentration coefficient of materials; $\sigma$ is the axial stress; and $t$ is the time variable [45].

In equation (2), $\Delta \sigma$ has a positive relationship with $l$. Generally, with an increase of the coal gangue particle size, the CGFB in the composite sample generally contains more defects with large scales. Under the same conditions, $\Delta \sigma$ around the defects in the CGFB with large coal gangue particle size is larger than that with small coal gangue particle size. On the other hand, the tensile strength of CGFB decreases with the coal gangue particle size [56]. Therefore, it is easier for natural defects in CFGB with large coal gangue particle size to develop macrotensile cracks under uniaxial loading. More macrotensile cracks form on the surface of CGFB. This aggravates the damage accumulation in the CGFB. And the CGFB becomes more broken after failure. 
Consequently, the strength of the composite sample decreases with the coal gangue particle size.

\section{Conclusions}

This investigation aims to study strength, AE, and failure characteristics of the coarse sandstone-CGFB composite samples with different coal gangue particle sizes under uniaxial loading. The main conclusions are summarized as follows:

(1) With an increase of the coal gangue particle size, the UCS and elastic modulus of the composite sample generally decreased. Compared with group A (coal gangue particle size of $0 \sim 5 \mathrm{~mm}$ ), the average UCS values of groups B (coal gangue particle size of $5 \sim 10 \mathrm{~mm}$ ) and $\mathrm{C}$ (coal gangue particle size of $10 \sim 15 \mathrm{~mm}$ ) decrease by $20.40 \%$ and $40.45 \%$, respectively, and the corresponding average elastic moduli decreased by $10.44 \%$ and $22.09 \%$, respectively.

(2) The strength of the composite sample was mainly determined by that of CGFB in it, affected by the interactions with the coarse sandstone. The deformation of the coarse sandstone weakened the damage accumulation in CGFB, resulting in the strength of the composite sample larger than that of CGFB. The average UCS values of composite samples with coal gangue particle sizes of $0 \sim 5 \mathrm{~mm}, 5 \sim 10 \mathrm{~mm}$ and $10 \sim 15 \mathrm{~mm}$ increased by $10.78 \%, 14.98 \%$, and $12.70 \%$ compared with CGFB in them, respectively.

(3) AE event signal regularity of the composite sample under uniaxial loading was divided into three stages: rising period, calm period, and active period. The intensity and frequency of AE event signals in three periods were strengthened with the coal gangue particle size. The calm period can be taken as the precursory information for the failure and instability of composite sample under loading, whose duration became short with the coal gangue particle size. The rebound deformation of coarse sandstone caused the fluctuations of $\mathrm{AE}$ event signals at the later stage of active period.

(4) The failures of composite samples occurred within CGFB, and no obvious failures were found in the coarse sandstone. CGFB mainly experienced the splitting failure accompanying by varying degrees of local surface spalling failures. The broken degree of CGFB was enhanced with the coal gangue particle size. The largest weight ratio of CGFB fragments (chips) after failure was determined by the coal gangue particle size.

\section{Data Availability}

The data used to support the findings of this study are included within the article.

\section{Conflicts of Interest}

The authors declare no conflicts of interest.

\section{Acknowledgments}

This work was supported by the National Key R\&D Programme (2018YFC0604704), National Natural Science Foundation of China (51904167 and 51874189), Taishan Scholars Project, Taishan Scholar Talent Team Support Plan for Advantaged \& Unique Discipline Areas, SDUST Research Fund, Open Research Fund of Key Laboratory of Safety and High-efficiency Coal Mining (JYBSYS2019201), and Technology Top Talent Support Project of Guizhou Provincial Education Department ([2017]098).

\section{References}

[1] S. Chen, D. Yin, F. Cao, Y. Liu, and K. Ren, "An overview of integrated surface subsidence-reducing technology in mining areas of China," Natural Hazards, vol. 81, no. 2, pp. 1129-1145, 2016.

[2] A. A. Baryakh, E. A. Telegina, N. A. Samodelkina, and S. Y. Devyatkov, "Prediction of the intensive surface subsidences in mining potash series," Journal of Mining Science, vol. 41, no. 4, pp. 312-319, 2005.

[3] X. Cui, J. Wang, and Y. Liu, "Prediction of progressive surface subsidence above longwall coal mining using a time function," International Journal of Rock Mechanics and Mining Sciences, vol. 38, no. 7, pp. 1057-1063, 2001.

[4] J. H. Park, M. Edraki, D. Mulligan, and H. S. Jang, "The application of coal combustion by-products in mine site rehabilitation," Journal of Cleaner Production, vol. 84, pp. 761-772, 2014.

[5] B. Ercikdi, A. Kesimal, F. Cihangir, H. Deveci, and İ. Alp, "Cemented paste backfill of sulphide-rich tailings: importance of binder type and dosage," Cement and Concrete Composites, vol. 31, no. 4, pp. 268-274, 2009.

[6] F. Ren, C. Zhu, and M. He, "Moment tensor analysis of acoustic emissions for cracking mechanisms during schist strain burst," Rock Mechanics and Rock Engineering, vol. 53, no. 1, pp. 153-170, 2019.

[7] Y. Zhang, S. Cao, N. Zhang, and C. Zhao, “The application of short-wall block backfill mining to preserve surface water resources in northwest China," Journal of Cleaner Production, vol. 261, Article ID 121232, 2020.

[8] N. Zhang, W. Liu, Y. Zhang, P. Shan, and X. Shi, "Microscopic pore structure of surrounding rock for underground strategic petroleum reserve (SPR) caverns in bedded rock salt," Energies, vol. 13, no. 7, p. 1565, 2020.

[9] X. Wang, C. Liu, S. Chen, L. Chen, K. Li, and N. Liu, "Impact of coal sector's de-capacity policy on coal price," Applied Energy, vol. 265, Article ID 114802, 2020.

[10] X. Du, G. Feng, Y. Zhang, Z. Wang, Y. Guo, and T. Qi, "Bearing mechanism and stability monitoring of cemented gangue-fly ash backfill column with stirrups in partial backfill engineering," Engineering Structures, vol. 188, pp. 603-612, 2019.

[11] X. Du, G. Feng, T. Qi, Y. Guo, Y. Zhang, and Z. Wang, "Failure characteristics of large unconfined cemented gangue backfill structure in partial backfill mining," Construction and Building Materials, vol. 194, pp. 257-265, 2019.

[12] Q.-1. Zhang and X.-m. Wang, "Performance of cemented coal gangue backfill," Journal of Central South University of Technology, vol. 14, no. 2, pp. 216-219, 2007.

[13] X. Zhang, J. Lin, J. Liu, F. Li, and Z. Pang, "Investigation of hydraulic-mechanical properties of paste backfill containing 
coal gangue-fly ash and its application in an underground coal mine," Energies, vol. 10, no. 9, p. 1309, 2017.

[14] B. C. Deng, H. Q. Zhou, and R. J. He, "Experimental research on coal gangue paste filling material," Journal of Mining and Safety Engineering, vol. 23, no. 4, pp. 460-463, 2006.

[15] W. Zhu, J. Xu, J. Xu, D. Chen, and J. Shi, "Pier-column backfill mining technology for controlling surface subsidence," International Journal of Rock Mechanics and Mining Sciences, vol. 96, pp. 58-65, 2017.

[16] J. L. Xu, D. Y. Xuan, W. B. Zhu, X. Z. Wang, B. L. Wang, and H. Teng, "Study and application of coal mining with partial backfilling," Journal of China Coal Society, vol. 40, no. 6, pp. 1303-1312, 2015.

[17] X. Zhu, G. Guo, H. Liu, T. Chen, and X. Yang, "Experimental research on strata movement characteristics of backfill-strip mining using similar material modeling," Bulletin of Engineering Geology and the Environment, vol. 78, no. 4, pp. 2151-2167, 2019.

[18] S. J. Chen, D. W. Yin, B. N. Hu, H. S. Yang, and X. W. Yin, "Study on mechanical characteristics of composite system of hard roof and filling body under strip filling," Journal of Mining and Safety Engineering, vol. 37, no. 1, pp. 110-117, 2020.

[19] M. Z. Du, T. H. Kang, B. Yi, and L. L. Wu, "Physic-mechanical properties of fly ash filling material at early age and its hydration process," Chinese Journal of Rock Mechanics and Engineering, vol. 35, no. 4, pp. 826-836, 2016.

[20] T. Y. Qi, G. R. Feng, Y. R. Li, Y. X. Guo, J. Guo, and Y. J. Zhang, "Effects of fine gangue on strength, resistivity, and microscopic properties of cemented coal gangue backfill for coal mining," Shock and Vibration, vol. 2015, Article ID 752678, 11 pages, 2015.

[21] T. Qi, G. Feng, Y. Zhang, J. Guo, and Y. Guo, "Effects of fly ash content on properties of cement paste backfilling," Journal of Residuals Science \& Technology, vol. 12, no. 3, pp. 133-141, 2015.

[22] G. R. Feng, X. Q. Jia, Y. X. Guo et al., "Influence of the wasted concrete coarse aggregate on the performance of cemented paste backfill," Journal of China Coal Society, vol. 40, no. 6, pp. 1320-1325, 2015.

[23] G. R. Feng, T. Y. Qi, X. J. Du, Z. H. Wang, and Y. J. Zhang, "Acoustic emission and ultrasonic characteristics in the failure process of cemented waste concrete-coal gangue backfilling (CWCGB) under uniaxial loading," Advances in Civil Engineering, vol. 2018, Article ID 8960806, 12 pages, 2018.

[24] G. Feng, X. Du, and Y. Zhang, ““Optical-acoustic-stress” responses in failure progress of cemented gangue-fly ash backfill material under uniaxial compression," Nondestructive Testing and Evaluation, vol. 34, no. 2, pp. 135-146, 2019.

[25] Q. Sun, X. D. Zhang, and Y. Yang, "Creep constitutive model of cemented body used in backfilling mining," Journal of China Coal Society, vol. 38, no. 6, pp. 994-1000, 2013.

[26] Q. Sun, B. Li, S. Tian, C. Cai, and Y. Xia, "Creep properties of geopolymer cemented coal gangue-fly ash backfill under dynamic disturbance," Construction and Building Materials, vol. 191, pp. 644-654, 2018.

[27] D. Wu, T. Deng, and R. Zhao, "A coupled THMC modeling application of cemented coal gangue-fly ash backfill," Construction and Building Materials, vol. 158, pp. 326-336, 2018.

[28] D. Wu, G. H. Sun, and Y. C. Liu, "Modeling the thermohydro-chemical behavior of cemented coal gangue-fly ash backfill," Construction and Building Materials, vol. 111, pp. 522-528, 2016.
[29] D. Wu, Y. Hou, T. Deng, Y. Chen, and X. Zhao, "Thermal, hydraulic and mechanical performances of cemented coal gangue-fly ash backfill," International Journal of Mineral Processing, vol. 162, pp. 12-18, 2017.

[30] D. Wu, B. Yang, and Y. Liu, "Transportability and pressure drop of fresh cemented coal gangue-fly ash backfill (CGFB) slurry in pipe loop," Powder Technology, vol. 284, pp. 218-224, 2015.

[31] B. Q. Cui, Y. Liu, H. Guo, Z. X. Liu, and Y. Li, "Experimental study on the durability of fly ash-based filling paste in environments with different concentrations of sulfates," Advances in Material Sciences and Engineering, vol. 2018, Article ID 24315345, 12 pages, 2018.

[32] Y. Liu, Y. Lu, C. Wang et al., "Effect of sulfate mine water on the durability of filling paste," International Journal of Green Energy, vol. 15, no. 13, pp. 864-873, 2018.

[33] Q. Sun, X. L. Li, X. Wei, and Q. W. Mu, "Experimental study of the influence of chloride corrosion on creep properties of filling paste," Journal of Experimental Mechanics, vol. 30, no. 4, pp. 231-238, 2015.

[34] Q. Sun, C. Cai, S. Zhang et al., "Study of localized deformation in geopolymer cemented coal gangue-fly ash backfill based on the digital speckle correlation method," Construction and Building Materials, vol. 215, pp. 321-331, 2019.

[35] Q. Sun, S. Tian, Q. Sun et al., "Preparation and microstructure of fly ash geopolymer paste backfill material," Journal of Cleaner Production, vol. 225, pp. 376-390, 2019.

[36] Y. A. Fishman, "Features of shear failure of brittle materials and concrete structures on rock foundations," International Journal of Rock Mechanics and Mining Sciences, vol. 45, no. 6, pp. 976-992, 2008.

[37] V. Sujatha and J. M. C. Kishen, "Energy release rate due to friction at bimaterial interface in dams," Journal of Engineering Mechanics, vol. 129, no. 7, pp. 793-800, 2003.

[38] Y. A. Fishman, "Stability of concrete retaining structures and their interface with rock foundations," International Journal of Rock Mechanics and Mining Sciences, vol. 46, no. 6, pp. 957-966, 2009.

[39] H. Zhong, E. T. Ooi, C. Song, T. Ding, G. Lin, and H. Li, "Experimental and numerical study of the dependency of interface fracture in concrete-rock specimens on mode mixity," Engineering Fracture Mechanics, vol. 124-125, pp. 287-309, 2014.

[40] X. Chang, J. Lu, S. Wang, and S. Wang, "Mechanical performances of rock-concrete bi-material disks under diametrical compression," International Journal of Rock Mechanics and Mining Sciences, vol. 104, pp. 71-77, 2018.

[41] S. J. Chen, D. W. Yin, B. L. Zhang, H. F. Ma, and X. Q. Liu, "Mechanical characteristics and progressive failure mechanism of roof-coal pillar structure," Chinese Journal of Rock Mechanics and Engineering, vol. 36, no. 7, pp. 1588-1598, 2017.

[42] S. J. Chen, D. W. Yin, N. Jiang, F. Wang, and Z. H. Zhao, "Mechanical properties of oil shale-coal composite samples," International Journal of Rock Mechanics and Mining Sciences, vol. 123, Article ID 104120, 2019.

[43] S. J. Chen, D. W. Yin, N. Jiang, F. Wang, and W. J. Guo, "Simulation study on effects of loading rate on uniaxial compression failure of composite rock-coal layer," Geomechanics and Engineering, vol. 17, no. 4, pp. 333-342, 2019.

[44] D. W. Yin, S. J. Chen, W. B. Xing, D. M. Huang, and X. Q. Liu, "Experimental study on mechanical behavior of roof-coal pillar structure body under different loading rates," Journal of China Coal Society, vol. 43, no. 5, pp. 1249-1257, 2018. 
[45] X. Z. Lyu, Z. H. Zhao, X. J. Wang, and W. M. Wang, "Study on the permeability of weakly cemented sandstones," Geofluids, vol. 2019, Article ID 8310128, 14 pages, 2019.

[46] A. P. Cheng, Y. S. Zhang, S. Y. Dai, F. S. Dong, W. X. Zeng, and L. D. Feng, "Space-time evolution of acoustic emission parameters of cemented backfill and its fracture prediction under uniaxial compression," Rock and Soil Mechanics, vol. 40, no. 8, pp. 2965-2974, 2019.

[47] D. K. Liu, Z. L. Gu, R. X. Liang et al., "Impacts of pore-throat system on fractal characterization of tight sandstones," Geofluids, vol. 2020, Article ID 4941501, 17 pages, 2020.

[48] J. Wang, S.-c. Li, L.-p. Li, P. Lin, Z.-h. Xu, and C.-1. Gao, "Attribute recognition model for risk assessment of water inrush," Bulletin of Engineering Geology and the Environment, vol. 78, no. 2, pp. 1057-1071, 2019.

[49] D. Ren, D. Zhou, D. Liu, F. Dong, S. Ma, and H. Huang, "Formation mechanism of the upper triassic Yanchang formation tight sandstone reservoir in Ordos Basin-Take Chang 6 reservoir in Jiyuan oil field as an example," Journal of Petroleum Science and Engineering, vol. 178, pp. 497-505, 2019.

[50] P. Shan and X. Lai, "An associated evaluation methodology of initial stress level of coal-rock masses in steeply inclined coal seams, Urumchi coal field, China," Engineering Computations, vol. 37, no. 6, pp. 2177-2192, 2020.

[51] C. Zhu, M. C. He, M. Karakus, X. B. Cui, and Z. G. Tao, "Investigating toppling failure mechanism of anti-dip layered slope due to excavation by physical modelling," Rock Mechanics and Rock Engineering, 2020.

[52] J. Xu, A. Haque, W. Gong et al., "Experimental study on the bearing mechanisms of rock-socketed piles in soft rock based on micro X-ray CT analysis," Rock Mechanics and Rock Engineering, vol. 53, no. 8, pp. 3395-3416, 2020.

[53] J. Xu, G. Dai, W. Gong, Q. Zhang, A. Haque, and R. P. Gamage, "A review of research on the shaft resistance of rock-socketed piles," Acta Geotechnica, 2020.

[54] H. Y. Pan, D. W. Yin, N. Jiang, and Z. G. Xia, "Crack initiation behaviors of granite specimens containing crossing-doubleflaws with different lengths under uniaxial loading," Advances in Civil Engineering, vol. 2020, Article ID 8871335, 13 pages, 2020.

[55] S. J. Chen, Y. Ge, D. W. Yin, and N. Jiang, “An experimental study of the uniaxial failure behaviour of rock-coal composite samples with pre-existing cracks in the coal," Advances in Civil Engineering, vol. 2019, Article ID 8397598, 12 pages, 2019.

[56] Z. Q. Yao, Q. L. Zhang, and G. Y. Hu, "Experimental study on tension strength characteristics of backfilling," Journal of University of South China (Science and Technology), vol. 23, no. 3, pp. 10-13, 2009. 